\title{
Study of histopathological and biochemical effect of Punica granatum $L$. extract on streptozotocin -induced diabetes in rabbits
}

\author{
E.R. Sarhat ${ }^{1}$, S.A. Wadi ${ }^{2 *}$, B.I. Sedeeq ${ }^{1}$, Th.R. Sarhat ${ }^{3}$ and N.A. Jasim ${ }^{2}$ \\ ${ }^{1}$ Department of Basic Science, Dentistry College, ${ }^{2}$ Department of Pharmacology, Collage of Veterinary Medicine, University \\ of Tikrit, Tikrit, ${ }^{3}$ Department of Biology, College of Education, University of Baghdad, Baghdad, Iraq \\ "email: Sihamwadee@tu.edu.iq
}

(Received May 7, 2018; Accepted July 22, 2018)

\begin{abstract}
This study was undertaken to determine the antidiabetic effects of oral administration of Punica granatum L. extract on serum and tissues of streptozotocin induced diabetic rabbits at $100 \mathrm{mg} / \mathrm{kg}$. The present study was carried out at the Faculty of veterinary Medicine, Tikrit University, from February to August 2017 for 10 weeks. For this purpose, 30 rabbits were randomly separated into three groups, each containing 10 animals: Group 1, healthy control rabbits; Group 2, diabetic rabbits received streptozotocin (STZ, $65 \mathrm{mg} / \mathrm{kg}$ ); Group 3, diabetic rabbits treated with PS extract (the $100 \mathrm{mg}$ PS+1 ml DW) for 21 days. At the end of experiment, blood samples were taken for measuring serum biochemical parameters. For histopathological evaluation, sections of kidneys were fixed in $10 \%$ buffered formalin and 5micron thick sections with H\&E stain were prepared using routine histopathological techniques. The treatment revealed that PSE extract significant decreased serum glucose thrombospondin-1, nitric oxide, alanine aminotransferase, aspartate aminotransferase, lactate dehydrogenase alkaline phosphatase, and C-reactive protein in diabetic treated rabbits as compared to diabetic rabbits. Histopathology of kidney showed lesions similar to human glomeruloscleroses, glomerular membrane thickening, arteriolar hyalinization and tubular necrosis. From the above one can conclude that PSE extract possess nephroprotective effect in experimentally induced diabetic rabbits.
\end{abstract}

Keywords: Histopathology, Punica granatum L., Extract, Rabbits Available online at http://www.vetmedmosul.com

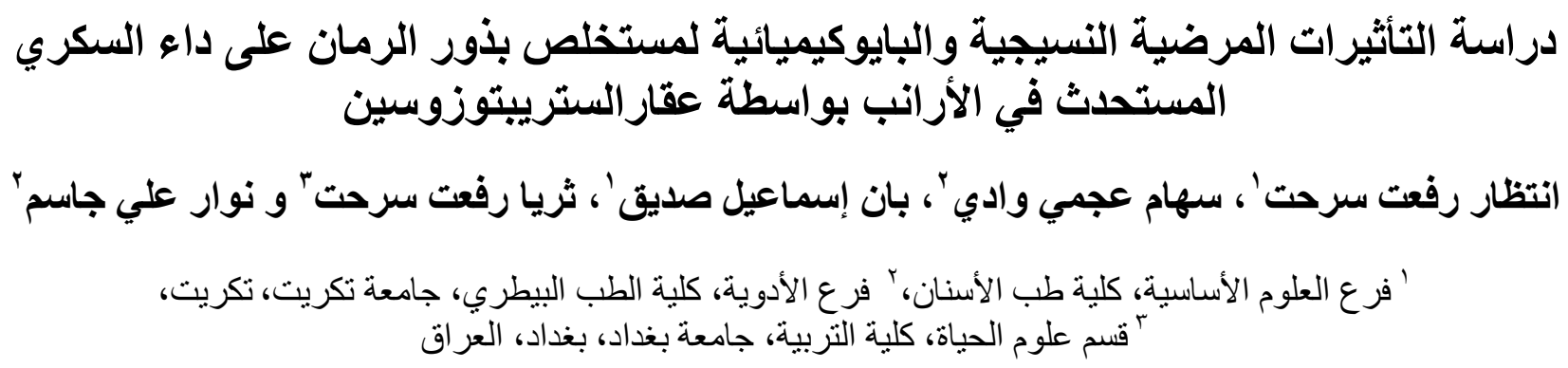

الخلاصة

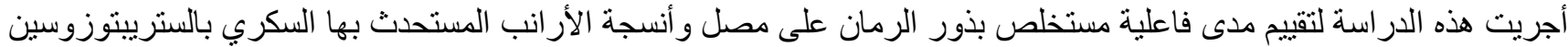

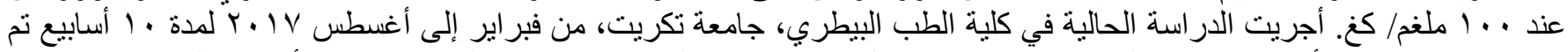

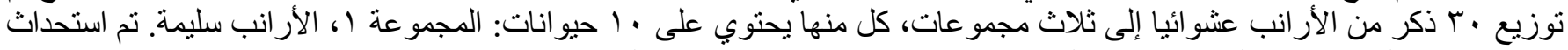

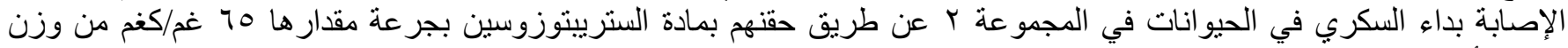

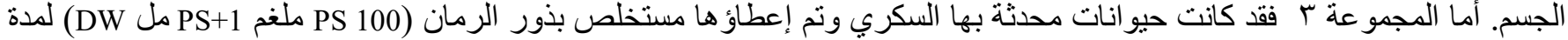

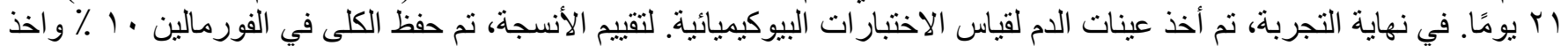

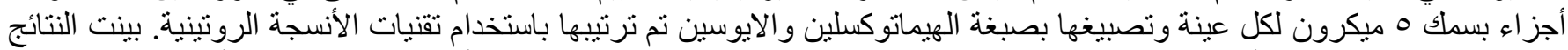
ان مستخلص بذور الرمان أدى إلى انخفاض كبير في مستويات سكر الدم، ثرومبوسبوندين- ا، و وأكسيد النيتريك، ناقلة أمين الالنين، وناقلة 


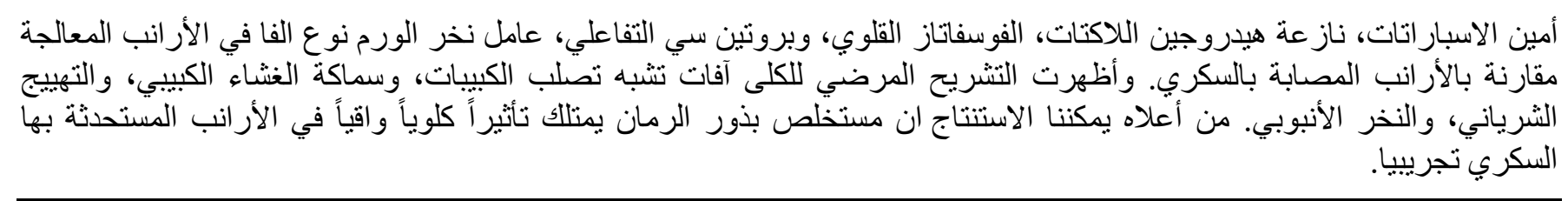

\section{Introduction}

In diabetes mellitus (DM), chronic hyperglycaemia produces multiple biochemical sequelae, characterized by hyperglycemia and hyperlipidemia, which have a severe impact on public health (1). It is well documented that chronic hyperglycaemia of diabetes is associated with longterm damage dysfunction and eventually the failure of organs especially the eyes, kidneys, nerves, heart and blood vessels (2). Many plant species are used in folk medicine for their hypoglycemic properties and therefore potentially used for treatment of DM, in this study we have selected Punica granatum L. to evaluate its anti-diabetic activity. Punica granatum L. (Punicaceae) (P. granatum) is commonly known as pomegranate contains diverse groups of polyphenols, including ellagitanins, gallotannins, and ellegic acid, as well as flavonoids, such as anthocyanins. However, its antioxidant activity is mainly due to hydrolysable tannin, including punicalagins, anthocyanins and ellagic acid $(3,4)$. Biological actions of pomegranate fruit that lead it to be considered as a healthy fruit are due to its potent phytochemicals contents that scavenge wide spectrum of free radicals (5). This great action of pomegranate is ascribed to a large number of phytochemicals therein including hydrolysable tannins and phenolic compounds found in different parts of this miracle fruit $(6,7)$. Numerous studies were carried out to investigate the effects of natural products on diabetes induced by streptozotocin. The pomegranate has been considered beneficial to health because of its high antioxidant content (8). The aim of the present study was to investigate the potential ameliorative effect of PSE in serum and tissues of streptozotocin induced diabetic rabbits.

\section{Materials and methods}

\section{Preparation of plant extract}

The pomegranates fresh fruits ( $P$. granatum $L$.) were washed and peeled. The peels and seeds were separated and air dried in an oven $\left(40^{\circ} \mathrm{C}, 24 \mathrm{~h}\right)$. After that, using a blender the dried materials turned into a powder. Thereafter, $500 \mathrm{~g}$ of pomegranate seed and pomegranate peel powders were separately extracted in methanol (Merck, Germany) (1:10 $\mathrm{w} / \mathrm{v}$ ) at $25^{\circ} \mathrm{C}$ for 24 and $96 \mathrm{~h}$, respectively. The mixture of each was then filtered throw $0.45 \mu$ pore size filters. The methanol was completely evaporated (rotary vacuum evaporator, Heidolph, Germany) at $40^{\circ} \mathrm{C}$. The PSE was stored in a deep freezer $\left(-70^{\circ} \mathrm{C}\right)$ until use (9).

\section{Induction of diabetes mellitus}

Diabetes was induced by a single intra-peritoneal injection of streptozotocin (Sigma, St. Louis, Mo, USA) at a dose of $65 \mathrm{mg} / \mathrm{kg}$ bodyweight. STZ was extemporaneously dissolved in $0.1 \mathrm{M}$ cold sodium citrate buffer, $\mathrm{pH} 4.5$. After $18 \mathrm{~h}$, animals with fasting blood glucose levels greater than $16.5 \mathrm{mmol} / \mathrm{L}$ were considered diabetic and then included in this study (10). Fasting blood glucose was estimated by using one touch glucometer (Accu-Chek sensor) of Roche Diagnostics, Germany.

\section{Animal stock}

Thirty rabbits (all male) weighing 1.5 to $2.45 \mathrm{Kg}$ were purchased from the college of veterinary medicine / Tikrit University, during February to August 2017. All the animals were housed in a cross-ventilated room (22 \pm $\left.2.5^{\circ} \mathrm{C}\right), 12 \mathrm{~h}$ light $12 \mathrm{~h}$ dark cycle) and were fed with standard diet (Grower's mash) and water ad-libitum. The animals were divided into three groups and were assigned randomly into each group that was made up of ten rabbits each housed in cages assigned to them. Group 1: was administered with normal saline $(5 \mathrm{ml} / \mathrm{kg}$ PO), and served as the (standard control). Group 2: contained streptozotocin induced diabetic rabbits, which were left untreated (single injection of $65 \mathrm{mg} / \mathrm{kg}$ streptozotocin, IP). Groups 3: received the $100 \mathrm{mg}$ PSE $+1 \mathrm{ml}$ DW per rabbits for 21 days.

The blood samples were collected and centrifuged (5000 rpm) and clear sera was separated and collected for the following investigations.

Thrombospondin-1, tumor necrosis factor- $\alpha$ and Creactive protein were measured by ELISA technique. The level of serum glucose, alanine aminotransferase, aspartate aminotransferase, alkaline phosphatase, and lactate dehydrogenase determined using a fully automated clinical chemistry analyzer (Abbott Architect C8000). Serum nitric oxide was estimated by the method of Smarason et al. (11).

\section{Statistical analysis}

Data were calculated as mean with standard deviation. One-way ANOVA was employed for statistical analysis with a significant level if $\mathrm{P}$ is $<0.05,<0.001<0.0001$. 


\section{Results}

The results depicted in Table 1 showed that there is significant increase in the TSP-1, NO, ALT, LDH, ALP, GGTP, TNF- $\alpha$, C-RP levels of diabetic group with respect to the control group. Whereas treatment with PSE extract led to a significant increment in the levels of glucose TSP1, NO, ALT, LDH, ALP, TNF- $\alpha$, C-RP compared with diabetic group.

Table 1: Effects of Punica granatum L. Extract on the serum biochemical parameters in rabbit

\begin{tabular}{lccc}
\hline Parameters & $\mathrm{NC}(\mathrm{G}: 1)$ & $\mathrm{DC}(\mathrm{G}: 2)$ & PSE (G:3) \\
\hline TSP-1 $(\mathrm{ng} / \mathrm{ml})$ & $1.791 \pm 0.1028 \mathrm{~b}$ & $11.060 \pm 1.526 \mathrm{a}$ & $3.800 \pm 0.894 \mathrm{~b}$ \\
NO $(\mu \mathrm{mol} / \mathrm{L})$ & $10.01 \pm 1.766 \mathrm{c}$ & $44.86 \pm 5.26 \mathrm{a}$ & $17.108 \pm 2.131 \mathrm{~b}$ \\
AST $(\mathrm{IU} / \mathrm{L})$ & $86.33 \pm 8.15 \mathrm{c}$ & $131.02 \pm 13.10 \mathrm{a}$ & $103.23 \pm 7.84 \mathrm{~b}$ \\
ALT $(\mathrm{IU} / \mathrm{L})$ & $47.4 \pm 2.052 \mathrm{c}$ & $197.70 \pm 8.01 \mathrm{a}$ & $83.27 \mathrm{~b} 4.76$ \\
LDH $(\mathrm{U} / \mathrm{L})$ & $326.57 \pm 21.25 \mathrm{c}$ & $597.60 \pm 26.29 \mathrm{a}$ & $417.00 \pm 17.38 \mathrm{~b}$ \\
ALP $(\mathrm{IU} / \mathrm{L})$ & $125.18 \pm 2.369 \mathrm{c}$ & $249.53 \pm 9.13 \mathrm{a}$ & $137.7 \pm 3.23 \mathrm{~b}$ \\
TNF- $\alpha(\mathrm{pg} / \mathrm{mL})$ & $21.05 \pm 1.569 \mathrm{c}$ & $38.427 \pm 1.945 \mathrm{a}$ & $28.37 \pm 1.579 \mathrm{~b}$ \\
C-RP $(\mathrm{mg} / \mathrm{liter})$ & $1.12 \pm 0.2446 \mathrm{c}$ & $2.66 \pm 0.2451 \mathrm{a}$ & $1.5570 \pm 0.2285 \mathrm{~b}$ \\
\hline
\end{tabular}

Rabbits in control group showed normal kidney architecture and histology (Figure 1). Sections of the kidney in diabetic rabbits showed, the hypertrophy of glomerular (Figure 2), arterioles appear constricted, the epithelial cells of the proximal and distal convoluted tubules are degenerated (Figure 3).

Sections of the kidney in diabetic rabbits treated with pomegranate showed, arterioles constricted, having thick wall, the epithelial cells of the proximal convoluted tubules are vacuolated (Figure 4), some of epithelial cells of the distal convoluted tubules degenerated, and some of the glomeruli are collapsed but most of them nearly return to normal number and diameter (Figure 5,6).

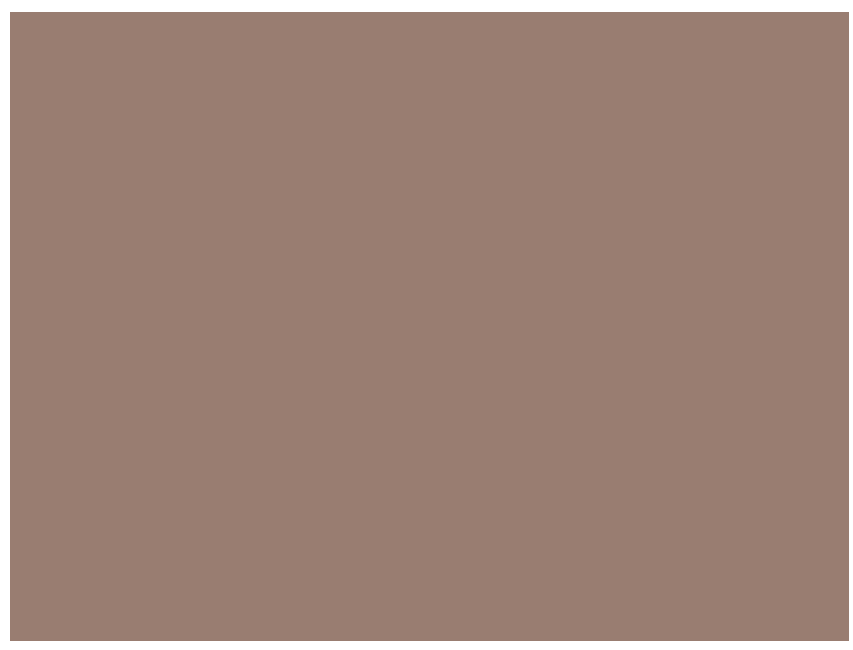

Figure 1: Demonstrating the shape of glomerulus (A), surrounded by a great number of proximal and distal convoluted tubules in control group $(\mathrm{G}: 1)(\mathrm{H} \& \mathrm{E} \times 20)$.

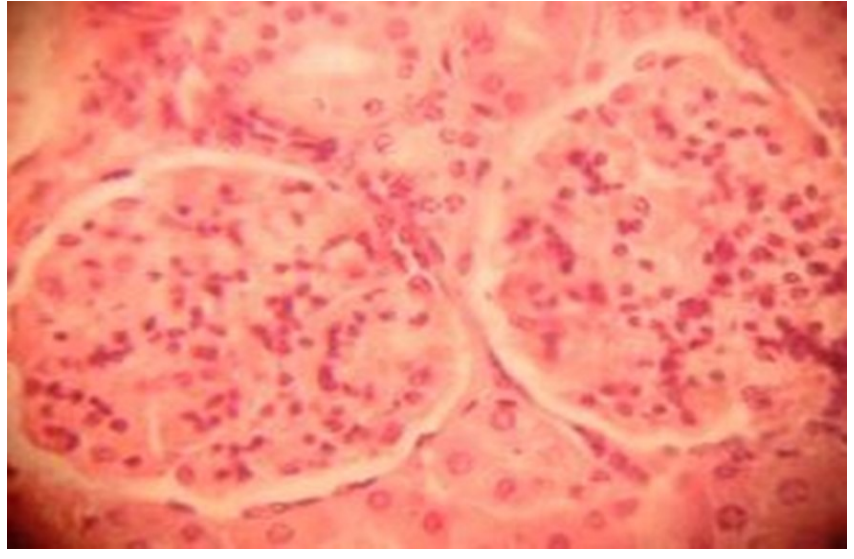

Figure 2: Hypertrophy of glomeruli in diabetic group (G:2) (H\&E, 40X).

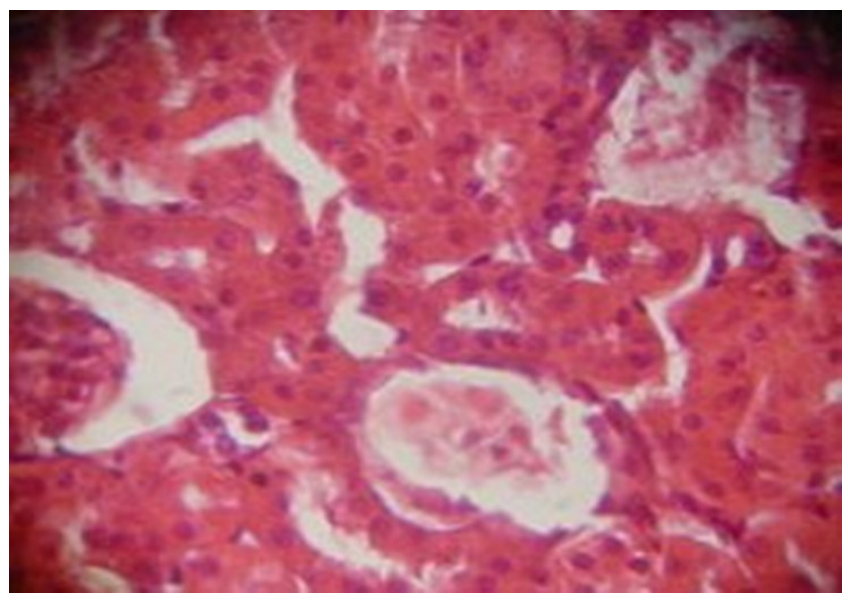

Figure 3: Degeneration of distal and proximal convoluted tubules (arrow) in diabetic group (G:2) (H\&E, 40X). 


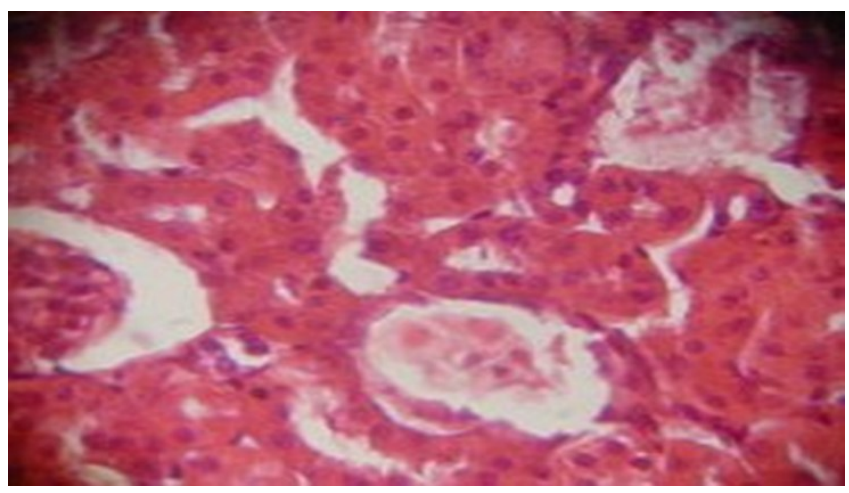

Figure 4: Vacuolation of the proximal convoluted tubules in treated group (G:3) (arrow) (H\&E, 75X).

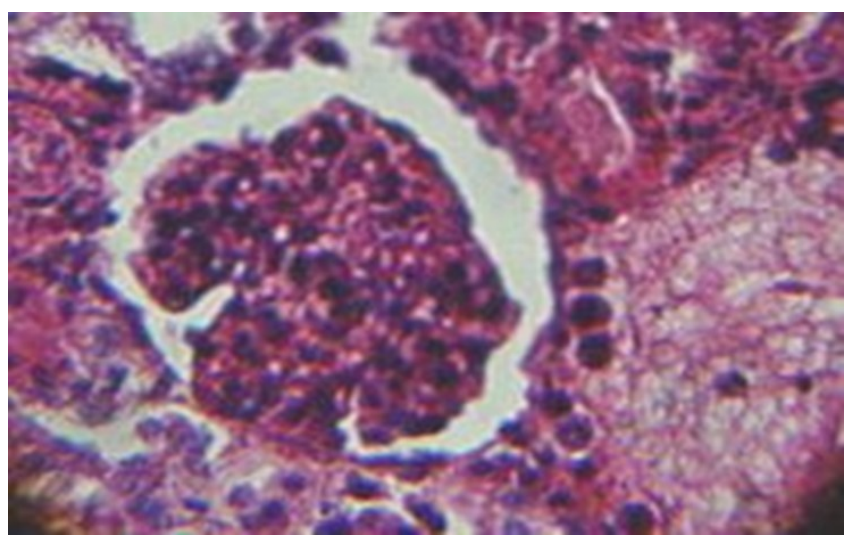

Figure 5: Vacuolation of the proximal convoluted tubules in treated group (arrow) (G:3) (H\&E, 75X).

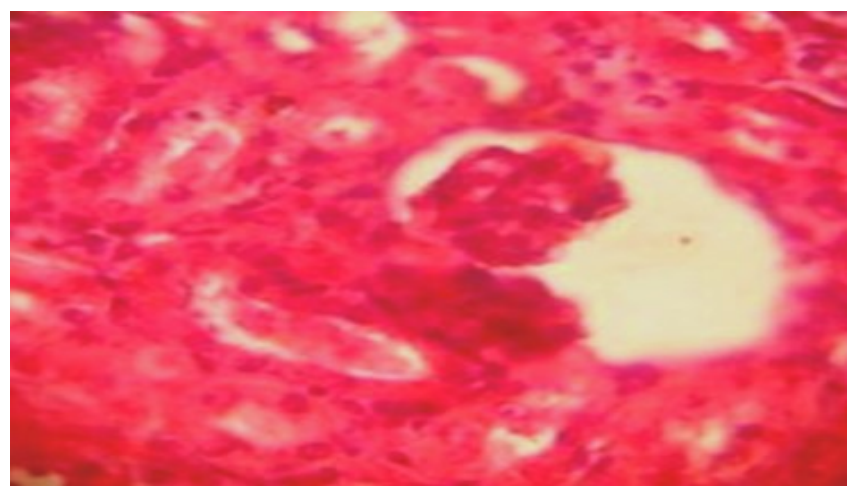

Figure 6: Shrinkage of glomerulus in treated group (G:3) (H\&E, 40X).

\section{Discussion}

The STZ-induced diabetic rats exhibited a significant hyperglycemia compared to non-diabetic control rabbits. This hyperglycemia resulted from selective cytotoxic effect of STZ on pancreatic $\beta$-cells which resulted in DM in experimental rabbits. It is proposed that, the cytotoxic effect of STZ be closely related to free radical generation in pancreatic - cells which interfered with the cellular metabolic oxidative mechanisms $(12,13)$.

The hypoglycemic effect of the tested extracts may be due to the active principles present in these extracts such as polyphenols and flavonoids (14) which possess the properties of regenerating pancreatic $\beta$ cell, increasing insulin secretion, enhancing glucose uptake by adipose or muscle tissues, inhibiting glucose absorption from intestine and glucose production from the liver and resolving the problem of insulin deficiency. these findings are in accordance with those of other study (15).

Thrombospondin-1 (TSP1) is a matricellular protein, first discovered in platelets. It is widely expressed in diverse tissues such as endothelial cells, monocytes and macrophages, smooth muscle cells, fibroblasts and adipocytes .TSP1 is readily measurable in human plasma and has a half-life of $9 \mathrm{~h}(16,17)$. Under physiological and pathological conditions TSP-1 is an endogenous inhibitor of angiogenesis It might be due to suppresses endothelial cell proliferation, migration, and tube-formation and induces endothelial apoptosis (18). TSP-1 controls homeostasis and tissue perfusion via regulation of nitric oxide signaling. Thus, the roles of TSP-1 in the regulation of angiogenesis are extremely complex and involve effects on stromal cells and the extracellular matrix (19).

Vascular smooth muscle cell (VSMC) from patients with diabetes exhibit increased proliferation, adhesion, and migration. Stimulating VSMCs through increased levels of TSP-1 in the diabetic vessel wall may explain the enhanced proliferation of VSMCs. Two mechanisms have been suggested for the effect of higher plasma TSP-1 level on atherosclerosis in patients with DM (20). First, dysfunction of endothelial cells (ECs) in patients with DM is well known (21) and TSP-1 certainly contributes to this dysfunction because of its antiproliferative and apoptotic effects on ECs (22). Second, although TSP-1 in diabetic vessels may affect metabolism of the luminal EC monolayer and VSMCs, the large amounts of TSP-1 present in the adventitia ultimately results in compromised growth and remodeling of the vasa vasorum.

Oxidative stress and overexpression of nitric oxide synthase (NOS) consider as interrelated contributing factors in pancreatic $\beta$-cell dysfunction (23). The marked decrease in NO level noticed in this study in the diabetic group, is in accordance with Chu (24), who reported that hyper glycaemia play a role in the decreased NO production in DM, because high glucose per se inhibited endothelial NOS activity in the glomeruli, through a protein kinase $\mathrm{C}$ associated mechanism (24). The decrease in production of NO due to reduced production of NO by NOS and inactivation of NO by ROS produced either by glycosylated 
proteins or directly from vascular endothelium as high level of HbA1c was observed in DM (25).

PSE is known as a powerful antioxidant and could improve diabetes-induced endothelial dysfunction. PSE can exert beneficial effects on the evolution of clinical vascular complications, coronary heart disease, and atherogenesis in humans by enhancing the endothelial NOS (NOSIII) bioactivity because the pomegranate juice reverts the potent down-regulation of the expression of NOSIII induced by oxidized low-density lipoprotein (oxLDL) in human coronary endothelial cells (26). PSE its capacity to protect NO against oxidative destruction and enhance the biological actions of nitric oxide. The results demonstrate that pomegranate juice was found to be a potent inhibitor of superoxide anion-mediated disappearance of nitric oxide (27).

In the present study, the mean CRP reductions were more pronounced in subjects supplemented with PS in comparison with the control group. C-reactive protein also appears to progressively increase when glucose metabolism deteriorates, as evident in subjects with Type2 DM (28).

The mechanisms of the anti-inflammatory properties of PSE are not clear. However, it has been suggested that PS inhibits the enzymes related to inflammation, such as peroxisome proliferator active receptors (PPARs), nuclear transcription factor kappa B (NF- $\mathrm{KB})$, and NSAID activated gene-1 (NAG-1), which reduces pro-inflammatory cytokine secretion through the inhibition of MAP kinases (29). Similar finding was observed by (30).

In the present study, the treatment of G3 with the PSE elicited significant decrease in serum ALT, AST, ALP, LDH, and GGT. The increase in aminotransferase levels may be attributed to cellular damage in the liver induced by diabetes. Cell damage results to increased permeability leading to the leakage of cytosolic enzymes into the blood (31). However, PSE produced a marked significant decrease of the elevated AST and ALT activities. This decrease may be attributed to the hepatoprotective and antioxidant activity of a number of flavonoids in the PSE.

This agrees with the report of Ghada (32). where it was reported that the effect of STZ-diabetes on ALP activity revealed a significant increase in ALP activity of STZ induced untreated rats. A marked decrease of serum and liver ALP activity of STZ-induced rats after treatment with JS indicates its protective effect over liver and improvement in liver function efficiency.

Histological examinations indicated that the kidney of diabetic control rats exhibited, decreased blood flow through the glomerular capillary system because of the thickening of the arteriole and arteriolar walls, and the consequent reduction in the Lumina of this vessels, produces chronic ischemia of the tubular system and reduces glomerular filtration if prolonged, this led to tissue shrinkage of the compounds of the glomerulus and atrophy of the tubules.

The mechanism of kidney destruction because of the oxidative stress involves the secretion of cytokines, mainly tumor necrosis factor TNF- $\alpha$, interleukin IL-1, and IFN-c. These alterations might be caused of abnormal production of cytokines and growth factors, which facilitate the synthesis of extracellular matrix proteins and the depositions in the glomerular level that finally lead to glomerular shrinkage, and glomerular basement thickening (33).

Treatment of STZ -induced diabetic rabbits with PSE extracts drastically improved kidney function as a result of its antithrombogenic action, which in turn controls the arachidonic acid cascade system (34). High level of antioxidant in pomegranate could boost to quenching of some free radicals inside cells, as well as have the capability to protect kidney and liver tissue from oxidative stress damage.

\section{Conclusion}

This study concluded that the PSE extracts may be capable of improving blood glucose TSP-1, ALT, LDH, ALP, TNF- $\alpha, C-R P$ levels has nephroprotective activity in streptozotocin-induced diabetic rabbits. Many questions related to antioxidant effect of PSE extract remain unanswered. Much more work is clearly needed before phytotherapy for diabetic nephropathy can be advanced to clinic.

\section{Acknowledgments}

The research was supported by college of dentistry and veterinary medicine, Tikrit University.

\section{References}

1. Entedhar R, Husamuldeen S. Effects of lycopene on paraoxonase and adipokines parameters in streptozotocin -induced diabetic rabbits. J Nat Med Sci. 2017;18(1):1-8.

2. Nacéra B, Rabah D, Imad A, El-Haci FL, Kebir B. Antihyperglycaemic effect of hydroalcoholic extract from Punica granatum L. peels in normal and streptozotocin-induced diabetic rats and its potent $\alpha$-amylase inhibitory. Der Pharma Chemica. 2010:2(6):416-428.

3. Shema-Didi L, Sela S, Ore L, Shapiro G, Geron R, Moshe G. One year of pomegranate juice intake decreases oxidative stress, inflammation, and incidence of infections in hemodialysis patients: A randomized placebo-controlled trial. Free Radic Biol Med. 2012;53:297-304.

4. Seeram NP, Aviram M, Zhang Y, Henning SM, Feng L, Dreher M. Comparison of antioxidant potency of commonly consumed Polyphenol-Rich beverages in the United States. J Agric Food Chem. 2008;56:1415-22.

5. Aviram M. Pomegranate juice as a major ssource for polyphenolic flavonoids and it is most potent antioxidant against LDL oxidation and atherosclerosis. Free Radic Res. 2002;36:71. 
6. Akhtar S, Ismail T, Fraternale D, Sestili P. Pomegranate peel and peel extracts: chemistry and food features. Food Chem. 2015;174:417-25.

7. Nuncio-Jauregui N, Munera-Picazo S, Calín-Sanchez Á, Wojdyło A, Hernandez F, Carbonell-Barrachina AA. Bioactive compound composition of pomegranate fruits removed during thinning. J Food Composit Analysis. 2015;37:11-9.

8. Nabil AS, Mohammed AQ, Turki AA, Muath AA, Abdullah AA. Ameliorative properties of Iranian Trigonella foenum - graecum L. seeds and Punica granatum L. peel extracts in streptozotocin-induced experimental diabetic guinea pigs. Asian Pac J Trop Biomed. 2017;7(3):234-239.

9. Mesgari AM, Heidari R, Amini AR, Zakeri milani P, Ghamarzad Shishavan N. Effects of pomegranate seed methanolic extract on methotrexate-induced changes in rat liver antioxidant compounds. Curr Top Nutraceutr. 2015;13(3):153-9.

10. Cheng DB, Liang B, Y Li. Antihyperglycemic effect of Ginkgo biloba extract in streptozotocin-induced diabetes in rats. Bio Med Res Intern J. 2013;1:1-7.

11. Entedhar R, Sarhat A, Ayhan R., Mohammed Sh. Effect of Glibenclamide and Tomato lycopene extract on some biochemical parameters in serum of alloxan Induced diabetic rabbits. Kirkuk Uni J Sci Stud. 2015;10(3):140-154.

12. Smarason AK, Allman KG, Young D, Redman CW. Elevated levels of serum nitrate, a stable end product of nitric oxide, in women with pre-eclampsia. Br J Obstet Gynaecol. 1997;104(1):538-543.

13. Papaccio GFA, Pisanti MV, Latronico E, Ammendola M, Galdieri A. Multiple low dose and single high dose treatments with streptozotocin do not generate nitric oxide. J Cell Biochem. 2000;77(1):82-91.

14. Bahadoran Z., Mirmiran P., Azizi F. Dietary polyphenols as potential nutraceuticals in management of diabetes: a review. J Diabetes Metab Disord. 2013;12; 43.

15. Aboonabi A, Rahmat A, Othman F. Effect of pomegranate on histopathology of liver and kidney on generated oxidative stress diabetic induced rats. J Cytol Histol .2014;6(1):2-5.

16. Lawler J. Thrombospondin-1 as an endogenous inhibitor of angiogenesis and tumor growth. J Cell Mol Med. 2002;6:1-12.

17. Zenaida LD, Kenneth P, Linda S. Thrombospondin-1: Multiple Paths to Inflammation. Med Inflam. 2011;(2):10.

18. Jimenez B, Volpert OV, Crawford SE, Febbraio M, Silverstein RL, Bouck N. Signals leading to apoptosis-dependent inhibition of neovascularization by thrombospondin-1. Nat Med. 2000;6:41-48.

19. Bauer EM, Qin Y, Miller TW, Bandle RW, Csanyi G, Pagano PJ, Bauer PM, Schnermann J, Roberts DD, Isenberg JS. Thrombospondin-1 supports blood pressure by limiting eNOS activation and endothelial-dependent vasorelaxation. Cardiovasc Res. 2010;88:471-481.
20. Stenina OI, Krukovets I, Wang K. Increased expression of thrombospondin-1 in vessel wall of diabetic zucker rat. Circul. 2003;107:3209-15.

21. Kirma C, Akcakoyun M, Esen AM. Relationship between endothelial function and coronary risk factors in patients with stable coronary artery disease. Circ J. 2007;71:698-702.

22. Nör JE, Mitra RS, Sutorik MM, Mooney DJ, Castle VP, Polverini PJ. Thrombospondin-1 induces endothelial cell apoptosis and inhibits angiogenesis by activating the caspase death pathway. J Vasc Res. 2000;37:209-18

23. Pitocco D, Zaccardi F, Di Stasio E, Romitelli F, Santini AS, Zuppi C. Oxidative stress, nitric oxide, and diabetes. Rev Diab Stud. 2010;7(1):15-25.

24. Chu S, Bohlen HG. High concentration of glucose inhibits glomerular endothelial eNOS through a PKC mechanism. Am J Physiol Renal Physiol. 2004;287(3):384- 392

25. Muniyappa R, Quon JM. Insulin action and insulin resistance in vascular endothelium. Curr Opin Clin Nutr Metab Care. 2007; 10 (4):523-530

26. De Nigris F, Williams IS, Botti C, Sica V, Ignarro LJ, Napoli C. Pomegranate juice reduces oxidized low-density lipoprotein downregulation of endothelial nitric oxide synthase in human coronary endothelial cells. Nitric Oxide. 2006;15(3):259-63.

27. Viuda MJ. Fernandez L, Alvarez JAP. Pomegranate and its many functional components as related to human health: A review. Compreh Rev Food Sci Food Saf. 2010;9:635-654.

28. Al-Hamodi Z, Al-Habori M, Al-Meeri A, Riyadh SA. Association of adipokines, leptin / adiponectin ratio and C-reactive protein with obesity and type 2 diabetes mellitus. Diabetol Met Syn. 2014;6:99

29. Yoon JH, Baek SJ. Molecular targets of dietary polyphenols with antiinflammatory properties. Yonsei Med J. 2005;46(5):585.

30. Asgary S, Keshvari M, Sahebkar A, Hashemi M, Rafieian KM. Clinical investigation of the acute effects of pomegranate juice on blood pressure and endothelial function in hypertensive individuals. ARYA Atheroscler. 2013;9(6):326-31.

31. Garella S. The cost of dialysis in the USA. Nephrol Dial Transplant. 1997;12:10-21.

32. Ghada Z, Soliman A. Anti-diabetic activity of dried moringaoleifera leaves in normal and streptozotocin (stz)-induced diabetic male rats. Indian J Appl Res. 2013;3:18-22

33. Baig MA, Gawali VB, Patil RR, Naik SR. Protective effect of herbomineral formulation (Dolabi) on early diabetic nephropathy in streptozotocin-induced diabetic rats. J Nat Med. 2012;66(3):500-9.

34. Yang JA, Choi JH, Rhee SJ. Effects of green tea catechin on phospholipase $\mathrm{A}_{2}$ activity and antithrombus in streptozotocin diabetic rats. J Nutr Sci Vitaminol. 1999:45:337-346. 